\title{
A Parapharyngeal Tumor with Coincidentally Diagnosed Contralateral Thyroid Tumor: A Rare Entity and Diagnostic Dilemma
}

\author{
Deepak Verma*, Uma G, Naveen S, Neha S, Surender K and \\ Kulvinder S \\ Department of Otorhinolaryngology, BPS Government Medical College for Women, \\ India
}

\section{Case Report \\ Volume 3 Issue 1}

Received Date: March 14, 2018

Published Date: March 29, 2018

DOI: $10.23880 /$ ooaj-16000164

*Corresponding author: Deepak Verma, Senior Resident, Department of Otorhinolaryngology, BPS Government Medical College for Women, HUDA sector-7, H.No 312, Gohana, Haryana, India, Tel: +918689037330; Email: dpkvrm20@gmail.com

\section{Abstract}

A rare case of primary parapharyngeal tumor with coincidentally diagnosed contralateral thyroid tumor is being reported here in an adult male who presented to ENT OPD with only complaint of pain during swallowing. Local examination revealed left tonsillar bulge with rest of the examination was within normal limits. Contrast enhanced MRI revealed an intensely enhancing lesion in left parapharyngeal space and coincidentally a small intensely enhancing right thyroid lobe nodule which on USG guided FNAC came out as Follicular neoplasm with Hurthle cell changes. The case is being reported for its rare presentation.

Keywords: Thyroid neoplasm; Hurthle cell neoplasm; Parapharyngeal space tumor; Schwannoma; Pleomorphic adenoma

Abbreviations: PPS: Parapharyngeal Space

\section{Introduction}

The parapharyngeal space is an inverted pyramidshaped region, extends from the skull base to the hyoid bone [1]. It is bound medially by the buccopharyngeal fascia and laterally by the ramus of the mandible with medial pterygoid muscle. This potential space is divided into prestyloid and poststyloid compartments by thick fascial layers extending from the styloid process to the tensor veli palatine muscle, called as the tensor-vascularstyloid fascia. The prestyloid compartment contains retromandibular portion of the parotid gland along with lymph nodes and adipose tissue while poststyloid region contains internal carotid artery, internal jugular vein, the 9th, 10th, 11th and 12th cranial nerves and the sympathic chain [2].

Tumors of parapharyngeal space account for only $0.5 \%$ of head and neck neoplasms. Only $20 \%$ of these tumors are malignant and $50 \%$ of these neoplasms arise from the 


\section{Otolaryngology Open Access Journal}

deep lobe of the parotid gland or minor salivary glands. While the most common lesion of the prestyloid space is the salivary gland neoplasms, especially pleomorphic adenoma of the parotid gland, the most common lesion of the poststyloid region is neurogenic lesions such as schwannomas and neurofibromas. Primary tumors (benign or malignant), metastatic lymph nodes from thyroid or nasopharyngeal malignancy, lymph node involvement by lymphoproliferative diseases and tumors arising from adjacent sites that secondarily extend into the parapharyngeal space are the four different types of neoplastic lesions of the parapharyngeal space [3].

Hurthle cell tumors of the thyroid (Askanazy cell tumors, oncocytomas or oxyphil tumors) are rare neoplasm accounting for less than $5 \%$ of all thyroid tumors [4]. They have also been found in association with various benign thyroid conditions such as Hashimoto's thyroiditis, hyperthyroidism, nodular goiter, and thyroid neoplasms; where they often represent oncocytic metaplasia. The behavior of Hurthle cell neoplasms are usually unpredictable $[5,6]$ and have no specific imaging characteristics. An isloated primary parapharyngeal tumor with a coincidental contralateral thyroid tumor is a rare finding as seen in our case. This case is being reported here for its rarity and management discussed.

\section{Case Report}

22 years old male electrician by occupation, presented with chief complaint of pain during swallowing from last 6 months which was insidious in onset, gradually progressive and associated with slight difficulty in swallowing specially with solid foods and slight heaviness in voice. It was not associated with fever, neck swelling, decreased mouth opening, foul smell from mouth, and difficulty in breathing, palpitation and sweating, weight or appetite loss. His medical and family histories were unremarkable. Local examination revealed left tonsillar bulge with smooth surface, non tender and does not bleed on palpation. There was no deviation of uvula and palatal movements were normal. Neck and laryngeal endoscopic examination didn't reveal any abnormality. All routine investigations including complete blood count with peripheral smear, thyroid function test and chest x-ray were normal. Intraoral FNAC from left tonsillar bulge was non conclusive. Contrast enhanced MRI revealed intensely enhancing lesion $(61 \times 39 \times 37 \mathrm{~mm})$ occupying left parapharyngeal and carotid space encasing ICA, abutting ECA and compressing/displacing oropharynx (Figure 1). It was hypointense on T1 and hyperintense on T2 with central fluid intensity suggestive of necrosis. There was a coincidental finding of an intensely enhancing occult right thyroid lobe lesion $(17 \times 15 \mathrm{~mm})$ was noticed which was earlier missed during neck examination due to small size of the tumor. USG guided FNAC from this thyroid nodule was in favour of Follicular neoplasm with Hurthle cell changes.

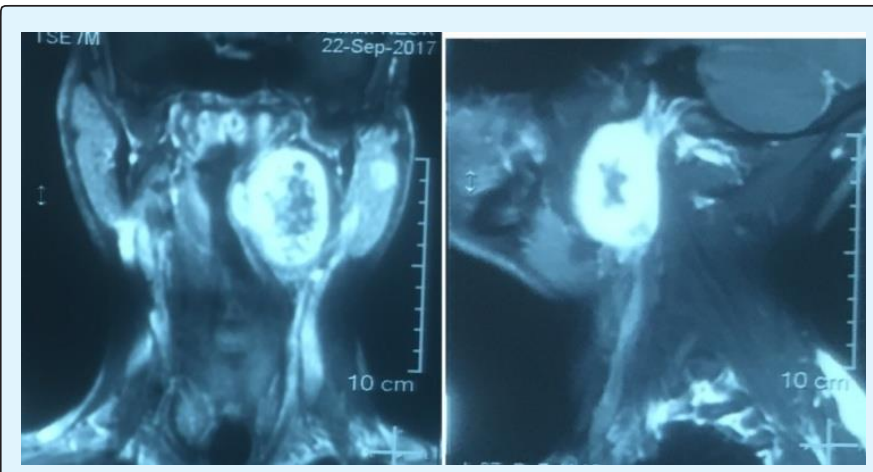

Figure 1: Contrast enhanced MR scan showing (L) intensely enhancing parapharyngeal mass.

Differential diagnoses kept in mind were: Thyroid and parapharyngeal space tumor both as separate entity, Thyroid or nasopharyngeal carcinoma with parapharyngeal space (PPS) metastasis. After thorough clinical and radiological evaluation patient underwent (R) hemithyroidectomy with (L) PPS tumor excision via transcervical approach (Figure 2). Specimen was sent for histopathological evaluation and came out as (L) parapharyngeal mass consistent with schwannoma and (R) hemithyroidectomy consistent with Hurthle cell carcinoma (minimal invasive). Patient underwent completion thyroidectomy and final histopathology came out as colloid goitre with focal hurthle cell changes. Patient is in regular follow up on thyroid replacement therapy (100 $\mu \mathrm{g}$ thyroxine daily) and doing fine without any complaints.

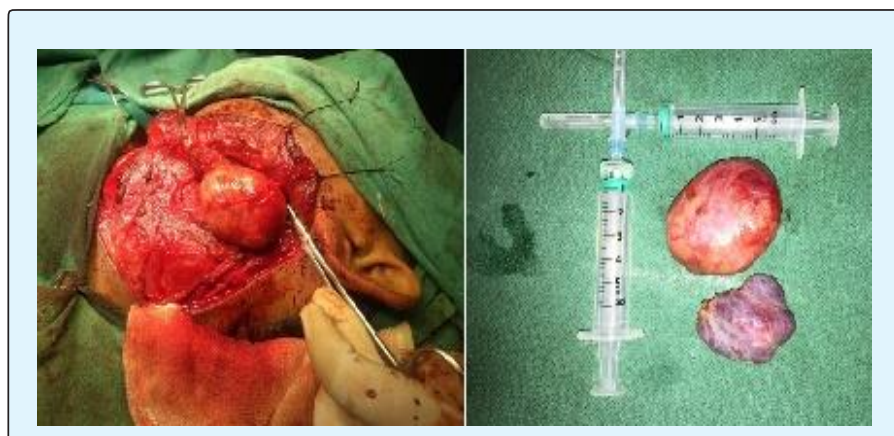

Figure 2: Intraoperative and postoperative pictures of specimen (both PPS tumor and thyroid. 


\section{Otolaryngology Open Access Journal}

\section{Discussion and Conclusion}

The PPS tumors usually present as asymptomatic neck mass or may present with symptoms of pain, dysphagia, trismus, dyspnea and obstructive sleep apnea, cranial nerve deficits leading to hoarseness and dysarthria, Horner syndrome (ptosis, miosis and anhydrosis). Clinical detection of early PPS lesions is difficult since small tumors are usually asymptomatic and the tumors size must be at least 2.5 to $3.0 \mathrm{~cm}$ to be detected clinically [7]. Also fullness or bulge in the tonsillar or soft palate region due to PPS tumor can be misdiagnosed as infections or tonsil tumors. In the presented case tumor was large enough to cause lateral pharyngeal and tonsillar bulge on left side. Initial evaluation of PPS masses should include a complete head and neck examination including laryngeal endoscopic examination, contrast CT and MRI scan, MRI angiography and laboratory studies for urinary vaniyll mandelic acid and metanephrine levels are useful investigations as seen in our case. Fine needle aspiration can be performed transorally, transcervically or guided by CT or ultrasound. Usually, the initial presentation of thyroid cancer is a palpable neck mass or a metastatic regional lymphadenopathy. However in some patients the tumor may be clinically occult and is incidentally recognized during radiology of the neck for some other lesion as seen in our case where thyroid nodule was seen on contrast MRI scan opposite to the side of parapharyngeal tumor. USG guided FNAC was done from the occult thyroid nodule which came out as Hurthle cell neoplasm. As we mentioned earlier, tumors of the PPS are usually salivary gland in origin or derived from local neurovascular structures within the space. Other less common neoplasms include chordoma, lipoma, lymphoma, chemodectoma, rhabdomyoma, chondrosarcoma, ameloblastoma, amyloid tumor, fibrosarcoma and plasmacytoma [8-10]. In this case the mass in the PPS was a primary follicular variant of thyroid papillary carcinoma. Although metastatic thyroid carcinomas in the PPS has been reported in literature, this case is unique as PPS tumor is isolated and contralateral to thyroid tumor excluding the suspicion of metastatic thyroid malignancy. Surgery is the main treatment of the parapharyngeal space tumors. The surgeon must be having detailed knowledge of parapharyngeal space anatomy, size and location of the mass, the relationship with great vessels and various surgical approaches for removing the mass. The surgical approaches can be transoral, transcervical, transparotid transcervical, the transcervical-transmandibular approach and the infratemporal approach. The preferred approach for the removal of the tumor of this case presented here was transcervical approach because this approach helped us to remove both the tumors easily with elongation of the incision in the neck and going till mastoid tip. This case report of primary parapharyngeal tumor with contralateral thyroid tumor is presented here to emphasize the importance of preoperative thorough clinical examination along with diagnostic radiological evaluation as the coincidentally diagnosed entity (thyroid tumor) turned out to be of more importance both for the patient as well as surgeon regarding management of such case. Majority of the tumors of Hurthle cells are benign and are called Huthle cell adenomas (HCAs). However, others are malignant and are called Hurthle cell carcinomas (HCCs) with aggressive nature. Thereby making it of surgical importance to have histopathological differentiation of HCAs from the carcinomas since thyroid lobectomy is recommended for HCAs and total thyroidectomy for HCCs as done in this case [11]. Metastatic thyroid tumor may be one of the differential diagnoses of parapharyngeal mass; however coincidental existence of primary tumors at both sites should always be kept in mind as seen in this case.

\section{References}

1. Attia A, El-Shafiey M, El-Shazly S, Shouman T, Zaky I (2004) Management of parapharyngeal space tumors at the National Cancer Institute, Egypt. J Egypt Natl Canc Inst 16(1): 34-42.

2. Lombardi D, Nicolai P, Antonelli AR, Maroldi R, Farina $D$, et al. (2004) Parapharyngeal lymph node metastasis: an unusual presentation of papillary thyroid carcinoma. Head Neck 26(2): 190-196.

3. Stell PM, Mansfield AO, Stoney PJ (1985) Surgical approaches to tumors of the parapharyngeal space. Am J Otolaryngol 6(2): 92-97.

4. Stojadinovic A, Hoos A, Ghossein RA, Urist MJ, Leung DH, et al. (2002) Hurthle cell carcinoma: A 60 -year experience. Ann Surg Oncol 9(2): 197-203.

5. Thompson NW, Dunn EL, Batsakis JG, Nishiyama RH (1974) Hurthle cell lesions of the thyroid gland. Surg Gynecol Obstet 139: 555-560.

6. McLeod MK, Thompson NW (1990) Hurthle cell neoplasms of the thyroid. Otolaryngol Clin North Am 23(3): 441-452.

7. Som PM, Biller HF, Lawson W, Sacher M, Lanzieri CF (1984) Parapharyngeal space masses: an updated 


\section{Otolaryngology Open Access Journal}

protocol based upon 104 cases. Radiology 153(1): $149-156$.

8. Work WP, Hybels RL (1974) A study of tumors of the parapharyngeal space. Laryngoscope 84(10): 17481755.

9. Fluur E (1964) Parapharyngeal tumors. Arch Otolaryngol 80: 557-565.
10. Shapiro RS, Stool SE, Snow JB, Chamorro H (1975) Parapharyngeal rhabdomyoma. Arch Otolaryngol 101(5): 323-326.

11. Chen HY, Benjamin LB, Chen MF (1996) Hurthle cell tumor. Int Surg 81: 168-170.

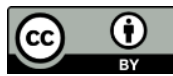

Deepak Verma, et al. A Parapharyngeal Tumor with Coincidentally Diagnosed Contralateral Thyroid Tumor: A Rare Entity and Diagnostic Dilemma. Otolaryngol Open Access J 2018, 3(1): 000164. 